\title{
Research on the Influence of Reclamation on Water and Sediment Environment Offshore
}

\author{
Cong Xin ${ }^{1}$, Zhu Wenjin ${ }^{1,}$, , Li Mingdong ${ }^{1}$, Tian Anguo ${ }^{1}$, Guo Jiangpei ${ }^{2}$, Gu Xinxin ${ }^{2}$ \\ ${ }^{1}$ School of Civil and Harbor Engineering, Huaihai Institute of Technology, Lianyungang, China \\ ${ }^{2}$ School of Mechanics and Civil Engineering, China University of Mining and Technology, Xuzhou, China
}

Email address:

top908019351@163.com (Cong Xin), zhuwj@hhit.edu.cn (Zhu Wenjin)

${ }^{*}$ Corresponding author

\section{To cite this article:}

Cong Xin, Zhu Wenjin, Li Mingdong, Tian Anguo, Guo Jiangpei, Gu Xinxin. Research on the Influence of Reclamation on Water and Sediment Environment Offshore. Journal of Water Resources and Ocean Science. Vol. 6, No. 4, 2017, pp. 55-60.

doi: 10.11648/j.wros.20170604.12

Received: July 7, 2017; Accepted: July 27, 2017; Published: August 30, 2017

\begin{abstract}
Reclamation changes the characteristics of water movement, then affects the marine environment system, and may even lead to environmental disasters. The influence on the 4 aspects of the current field, wave field, suspended sediment field and topography were summarized. Impacts of large area of reclamation project on the marine environment are found very few, and to expand the study scope and make up for the current lack of a wide range of studies on multiple reclamation impacts on the marine environment is an important research direction in the future; In the long time scale, it is a lack of long-term cumulative effects on coastal reclamation and whether the influence can restore; the present study focuses only on the impact evaluation of scope, type, and degree from lack of exploring the potential mechanism; It is a lack of interdisciplinary research, and the analysis of comprehensive influence of reclamation projects on land, sea and biological and ecological environment.
\end{abstract}

Keywords: Reclamation, Offshore, Hydrodynamic, Water and Sediment Environment

\section{Preface}

Reclamation refers to an engineering technology of building dike to settle along the river, lakeside and seaside. Coastal development was dominated by farmland and aquiculture in early reclamation whose proportion reduced relatively in medium term, and the proportion of port and urban construction with high economic value increased gradually in late development [1-3]. Reclamation has become an important measure to solve the contradiction between man and land and promote economic development in the coastal areas. Based on remote sensing and GIS technology, the total amount of reclamation shows a trend of decreasing first and then increasing in the past 1985-2010 years in China. Among them, reclamation intensity of the Bohai rim economic circle and the Yangtze River Delta Economic Zone was the largest whose total amount of reclamation accounted for $85.7 \%$ of the whole country [4]. The coastal reclamation intensity growth rate in the case study areas of Yellow River estuary from 2000 to 2015 is about $37.97 \%$ [5].
Because of China's rapid growth of reclamation area [6], coastal zone suitable for reclamation reduce drastically [7], and the focus of reclamation is gradually from the high to middle and low beaches which also fall sharply [8]. The reclamation project changes the hydrodynamic conditions and marine sediment conditions, which produce the change of tide flow field and deposition. And the greater reclamation area is, the greater the effect of hydrodynamic conditions are [9]. The impact on coast erosion, seabed topography, port and waterway siltation, estuary deposition, bay tidal volume and coastal beach stability and ecosystem [10-13] near reclamation project will be brought [14-21], which will be more and more serious [22] and aggravate the flood disaster in some areas in a certain extent [23].

Aiming at the present reclamation situation of Jiangsu in China, Zhang C K, et al. [24] proposed the development of coastal resources should follow the natural evolution, and the reclamation spatial layout should not damage the ecological environment, change the radial sandbanks dynamic model, affect the port berth and deepwater channel, and influence the estuary flood drainage. The impact of small range reclamation 
on water and sediment environment is researched in the present. And, as long as it is not the large scale reclamation and environmental impact assessment is well done before reclamation, the negative impacts of a single project on the water and sediment environment of estuary, coast, gulf, and near the island are not obvious, even can be neglected. However, for a coastal area, the cumulative effects of long-term heavy reclamation cannot be ignored [25].

Zhang C K, et al. [26] proposed reclamation layout should be in accordance with topography characteristics and water dynamic field, and the enough tide channel must be set aside to protect the smooth of the intersection of progressive and rotating tidal wave in the central area of radial sand ridges, maintaining the existing situation of dynamic-topography. However, the project essentially changes the characteristics of the water movement in the vicinity of the reclamation area, thus it affects the marine ecological environment system, and may even lead to environmental disasters. Therefore, the research and analysis of the impact of reclamation project is of great importance to optimize the overall layout and the scientific, effective and rational exploitation of resources [27-28]. Hydrodynamic conditions are the basis of sediment transport and topography evolution, therefore, it is necessary to study the changes of hydrological dynamic conditions before and after reclamation. It is shown in figure 1 of the coastal reclamation plan of Jiangsu province, China.

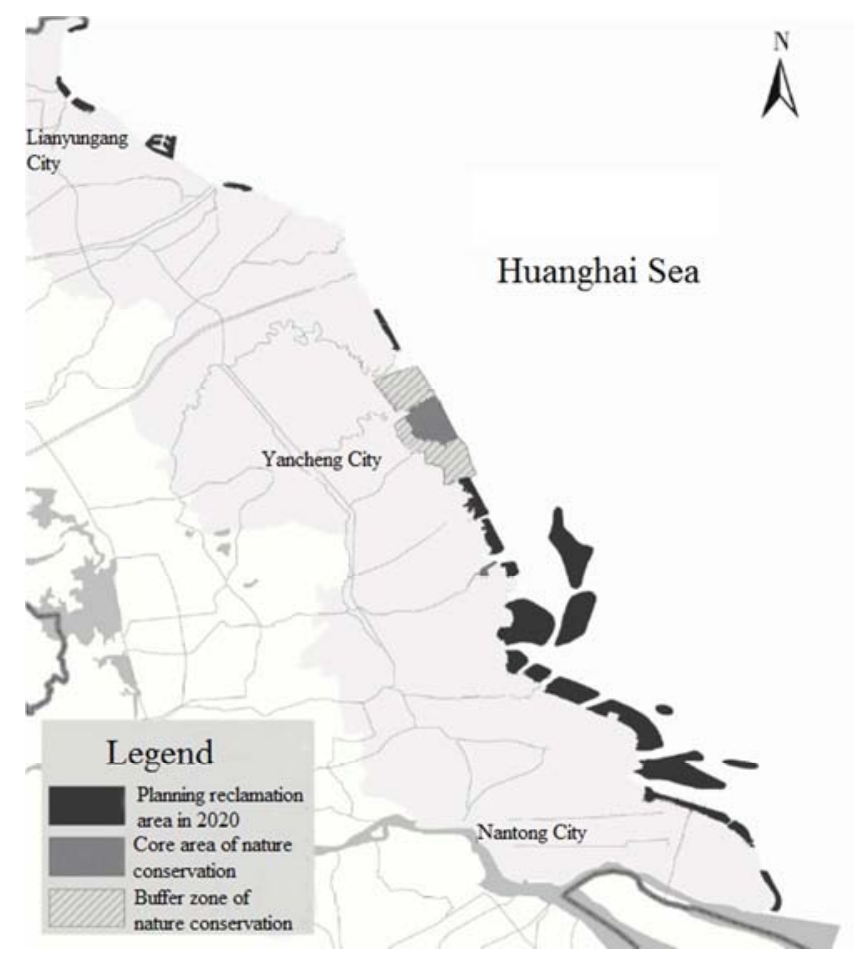

Figure 1. Plan of coastal reclamation project in Jiangsu Province, China.

\section{Research Status}

The reclamation project has changed the natural coastline, topography, bay area and other natural attributes of the sea, resulting in the changes of the water and sediment dynamic environment. With the development of computer technology, besides the analysis and comparison of data, the mathematical model is more and more widely applied to solve the apractical problems of offshore engineering [29]. The mutual effects of multi-factors such as wind, wave, tide, flow, salinity and sediment in wide-range estuary and coast can be solved by mathematical model whose application in coastal engineering in recent years has been paid more and more attention to.

\subsection{Research on the Influence on Tidal Flow Field}

As the reclamation narrows the bay's spatial scale and reduces the standing wave reflection distance, reclamation usually results in weakening tidal currents within the bay. Ou J, et al. [30] simulated the tide of Taizhou Bay before and after reclamation, and found that tide characteristics are basically unchanged and channel flow velocity isn't influenced after the reclamation project. Therefore, without changing the characteristics of the tide, the tidal resources can be developed and utilized.

Zhang Qin, et al. [31] studied the reclamation area of Taizhou Bay and found that the impact of tidal flat reclamation project on hydrodynamic characteristics was confined to the waters near the reclamation area. After the reclamation of large-scale tidal flat, the estuary narrows and the area of the water area reduces, which made the amplitude of M2 tidal wave near the reclamation area decrease and the tidal wave velocity of spreading to the shore slow down. The fluctuation urgent velocity of the waters near the reclamation area reduces greatly and the flow direction changes. The high water level of spring tide of sea area and the tidal volume of the estuary reduces to a certain extent. On the basis of the data in 2002, Chen D X, et al. [32] found that after the southern Oujiang reclamation, the maximum velocities of the flood and the ebb tide increase. Lv H N [33] studied the influence of Wenzhou offshore reclamation project on the hydrodynamic force of Oujiang Estuary by using the measured data in 2007 and POM model. It was found that the station's maximum ebb tide flow rate has the trend of reduction. In addition, the effect of the project on the M2 tide is not significant. In the vicinity of the sea area, most tides have northward trends, but the flow rate changes slightly. Song Z K, et al. [34] built the 2D vertical average tidal mathematical model of Yangtze Estuary-Hangzhou Bay by using Mike 21_FM. Based on the verification of the model using the measured data, the tidal field before and after the large-scale reclamation was simulated and analyzed in the north branch. It was found that after the large-scale reclamation, the average high tide level rises and the average low tide level reduces in the whole north branch. The velocity of the flood and ebb tide in the upstream and middle reaches of the river increases, and the downstream velocity decreases. Confluence of rising tidal currents of the north and south branches shift upward, and the tide power increases.

Tao J F, et al. [35] based on the numerical model of the 2D tidal current forecast in Jiangsu offshore waters, and carried out numerical simulation of 3 stages of Jiangsu coastal beach reclamation planning (2010-2020), taking the year of 2008 as 
the base level (status quo). The influence of the large-scale beach reclamation project on the tidal current in the coastal waters of Jiangsu Province was discussed from three aspects: the wave of main tidal constituent distribution, the tidal channel velocity and the change of the tidal volume of unit width. The numerical simulation results showed that after the reclamation project of 3 stages, amphidromic point of M2 shifts slightly to the northeast, coastal tidal wave propagation speed accelerates, and tidal wave expansion is enhanced. After the first and second stages of the reclamation project, the tidal prism of unit width of Xiyang channel increases by more than $10 \%$, and the fluctuation urgent velocity increases in rate of about $20 \%$. The tidal prism of unit width of other channels changes about $5 \%$, and the fluctuation urgent velocity changes slightly. After the third stage reclamation project, the tidal prism of unit width and the fluctuation urgent velocity of Xiyang channel increased by more than $20 \%$. But the tidal prism of unit width of Xiaomiaohong channel reduces by more than $20 \%$, and flow rate reduces about $10 \%$.

In recent years, the research and application of $3 \mathrm{D}$ model is becoming more and more wide, but because of the complexity of 3D simulation, most research results are obtained in the extension on the basis of two-dimensional, and 3D model require to know more conditions and its algorithms is complex, such as the processing of free surface and bed surface boundary condition, so the results are not necessarily more accurate than the 2D model. For large-scale sea area, 3D simulation is not much more practical and extensive than $2 \mathrm{D}$ simulation in engineering applications. A 3D finite element model for tide movement in the Adriatic Sea was established by Benoit [36], which was based on the improved equations. A 3D flow mathematic model of Tiaozini waters based on EFDC model was established by Liu X D [37] and the tidal flow fields before and after the Tiaozini reclamation were simulated. After first-stage reclamation project, it has little effect on the tidal flow field of radial sandbank while mainly increases the water blocking effect near the waters of engineering, resulting in the decrease of local velocity on the east side of dike. After the implementation of reclamation project, tidal level around Liangduo Estuary and Fangtang Estuary uplifts slightly, which obstructs the tide of north-south trend along the bank of engineering area. It has a certain impact on the direction of the flow of the coastal waters around the embankment in engineering area outside, but has little effect on the offshore flow field of radiating sandbar. In the perspective of tidal power, the reclamation project is feasible.

\subsection{Research on the Influence on Wave Field}

It was found through simulation by Wang Q, et al. [38] that the effective design wave height and the mean wave period of 50-year return period in Jiangsu coastal waters have a trend of reduction after the implementation of the reclamation planning project of Jiangsu coastal beach. They are basically unchanged in the north of Jiangsu, while vary a lot in the south. The advanced third generation wave model SWAN was used to study coastal Jiangsu by Fan C J [39]. It was found that after the implementation of the reclamation project, coastal beach changes. In the normal weather condition, the distribution of wave field in Jiangsu north and south waters is different. Wave height is mainly influenced by the Jiangsu coastal terrain. Contour lines of wind wave field are almost parallel with the isobaths in the northern waters while complicated in the southern waters, which reflects the underwater terrain changes to some extent. But when the typhoon transit, affected by the typhoon intensity and path, wave height contour distribution will change with time. After the reclamation planning of Jiangsu coastal beach was carried out, wave height and period vary slightly in the planning reclamation area of coastal northern Jiangsu while vary greatly in the southern coastal Jiangsu, but the influence is limited, and its magnitude is smaller.

\subsection{Research on the Influence on Suspended Silt Field}

The reclamation project of Zhoushan Island was studied by Ji Y J, et al. [40]. It was summarized that the fundamental changes of waterway and seabed erosion and deposition environment in the surrounding waters are caused by the sediment dynamic conditions. It changes from groove erosion and beach deposition before to dramatical siltation after reclamation, and the maximum waterway deposition thickness is up to $26 \mathrm{~m}$. According to the analysis, the reclamation project changes the suspended sediment transport model of waterway. Large amounts of sediment transport in a form of transit before reclamation while sand which is in and out the bay with flat ground formed by reclamation will be dominated by subsidence. The effect of reclamation on the deposition of tidal barrage [41] was researched by Gong Z [42]. Wang Port taken as an example, based on RS technology, it was found that reasonable plan of Wang Port is that reclamation of high beach should be between the average spring high tide level and the mean high tide level according to the direction of 30 to 45 degrees. Wang L S [43] studied the impact of reclamation on the sediment transport in estuaries and coastal waters of Wenzhou. It was found that due to the large long-term engineering reclamation area, the corresponding effect is largest, while the influence of medium and short-term projects are relatively small. Zhang R S [44] believes that reclamation in supratidal zone has little effect on the general tide in China's current conditions, and it has a certain influence in the storm tide or flood tide in autumn, but the solution is to increase 2-3 times of scouring.

A nested 2D flow and sediment mathematical model is established by Ke J, et al. [45] to predict the change of water and sediment environment caused by engineering plan in Lianyungang, Jiangsu province of China. The results show that the large-scale reclamation plan of Haizhou Bay has little influence on the water and sediment environment of extensiveness, and it doesn't change the tidal current movement and suspended sediment distribution characteristics. The effect mainly concentrate on the estuary of Linhong River, where tidal flow and high value region of suspended silt changes obviously. But in Liezi estuary and Xiuzhen estuary, the change caused by reclamation project is relatively small. Based on the nested 2D current sediment 
mathematical model, it was found that after reclamation the holistic tidal current and suspended sediment field of research area in Haizhou Bay changes slightly [46], but tidal prism decreases after reclamation, resulting in the decrease of flow velocity, and it is basically silted around the reclamation project area especially the left of the engineering, while Linhong Estuary is locally scoured. Based on the Mike 21 model, the siltation thickness under gate caused by reclamation is about $2 \mathrm{~cm}$, predicted by Yang D C, et al. [47]. It is found that the reclamation of Haizhou Bay will not cause the severe siltation of Linhong River Estuary gate, and the research scope and the distribution characteristics of observation points, feature points and characteristic section are shown in figure 2.

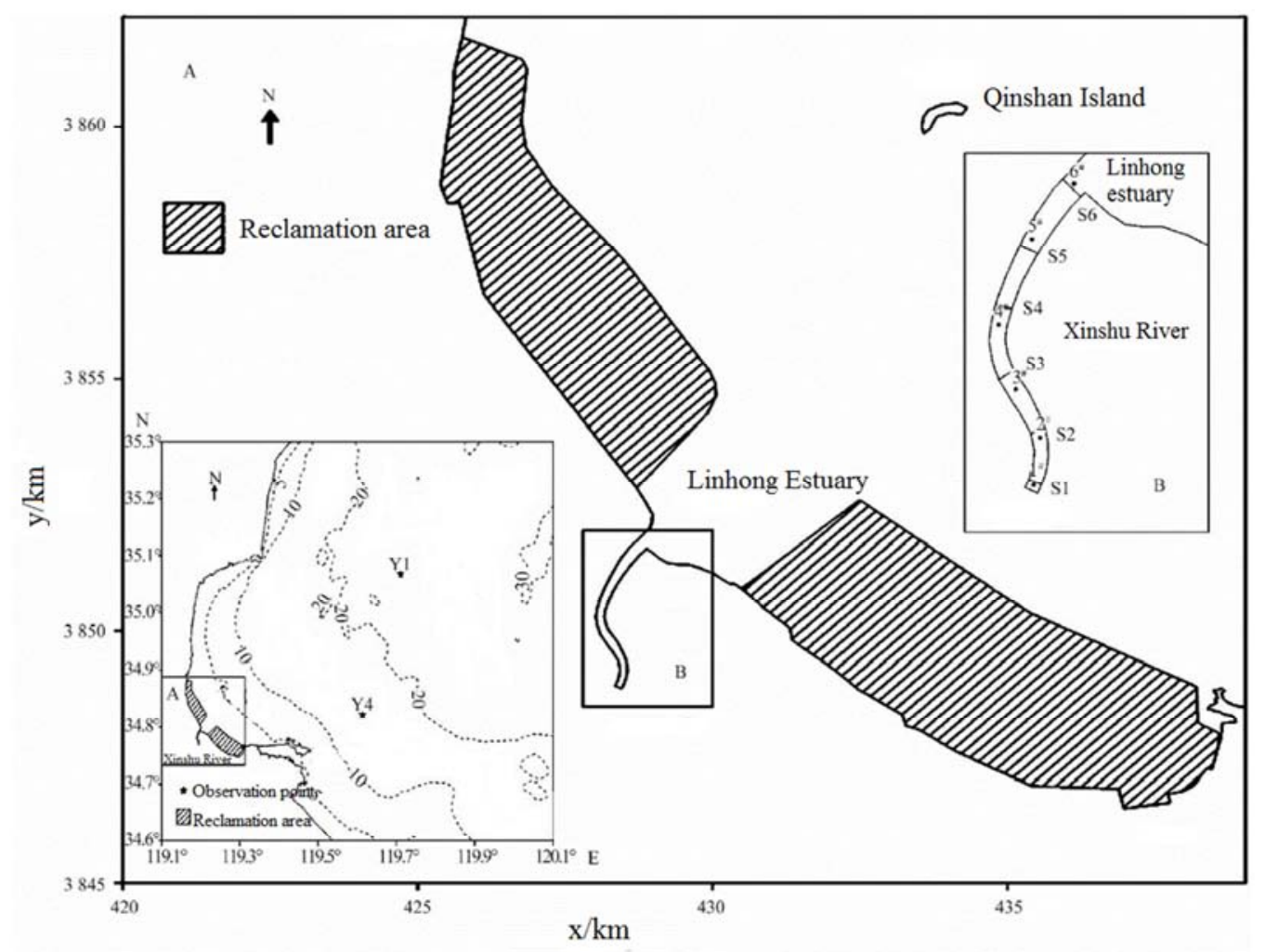

Figure 2. Research scope, observation points, characteristic points and characteristic section distribution of Haizhou Bay, Jiangsu Province.

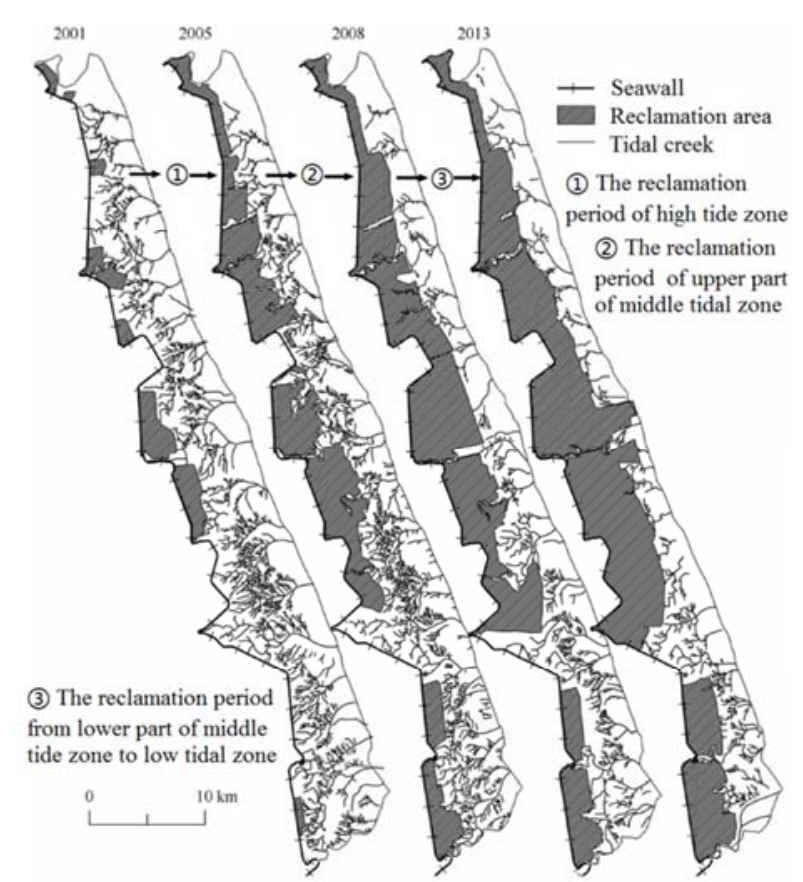

Figure 3. The distribution and variation of tidal creeks in the central Jiangsu research area.

\subsection{Research on the Influence on Terrain}

It was found that continuous reclamation will cause more and more narrow and steep tidal beach by Wang Y P, et al. [48] in coastal areas of Jiangsu, China. The width and slope of the tidal flat will not stop adjusting until the reclamation project is completed. In the study area of central Jiangsu, the tidal gully has obvious degradation and extinction trend under the influence of large-scale beach reclamation. In the whole reclamation process, the main drainage way of late ebb tide transforms gradually from tidal creek to the beach face [49], as shown in figure 3 . On the basis of satellite remote sensing image with high resolution at different periods, the dike line and the average high tide line were extracted rapidly by $\mathrm{Qu} \mathrm{W}$ $X$, et al. [50]. The influence of reclamation activities on the beach terrain of Sheyang estuary was analyzed. The results indicate that the method can effectively extract the information of dike line.

\section{Summary and Outlook}

Through the above analysis, the impact of reclamation project on the water and silt environment offshore is mainly 
focused on the researches on tidal current field, wave field, suspended silt field and topography. But there are many problems, which provide important reference for future research. Details are as follows.

(a) The aspects of predictive evaluation before reclamation planning and the changes of hydrodynamic environment after the completion of small scale reclamation project were mainly studied in China, and the influence of a large-scale reclamation on marine environment was seldom researched. Therefore, it is an important research direction to expand the research scope and make up for the lack of research on the impact of large-scale and multiple reclamation areas on marine environment.

(b) The researches on the influence of nearshore reclamation on water and silt environment are mostly focused on the comparison of the change of their characteristic parameters, but few studies have been conducted to measure their change process by timescale. In the long timescale, there is a lack of long-term cumulative impacts of nearshore reclamation and its performance of restoration. In the future, the time span should be enlarged and the influence process and cumulative effect should be studied more deeply.

(c) The present study only focuses on the range, species and extent of the impact of reclamation on marine environment, but the potential mechanism of the influence is less explained and explored.

(d) About the study depth, interdisciplinary cross study is less, the combined impact of reclamation projects on land, marine, biological and ecological environment cannot be in-depth analyzed.

\section{Acknowledgements}

National Natural Science Foundation of China (51609093); Jiangsu Natural Science Foundation of China (BK20130409); Jiangsu Provincial Department of Education Fund of China(16KJB560002).

\section{References}

[1] Zhang X X, Yan C Q, Xu P, et al. Historical evolution of tidal flat reclamation in the Jiangsu coastal areas [J]. ACTA GEOGRAPHICA SINICA，2013，68(11): 1549-1558. (In China)

[2] Gao Y, Wang H, Su F Z, et al. The analysis of spatial and temporal changes of the continental coastlines of China in recent three decades [J]. ACTA OCEANOLOGICA SINICA, 2013, 35(6): 31-42. (In China)

[3] Shen Y M, Feng N H, Zhou Q, et al. The status and its influence of reclamation on Jiangsu coast [J]. Marine Sciences, 2006, 30(10): 39-43. (In China)

[4] Wu W T, Tian B, Zhou Y X, et al. The trends of coastal reclamation in China in the past three decades [J]. ACTA ECOLOGICA SINICA, 2016, 36(16): 5007-5016. (In China)
[5] Xu Y, Cai Y, Sun T, et al. A multi-scale integrated modeling framework to measure comprehensive impact of coastal reclamation activities in Yellow River estuary, China [J]. Marine Pollution Bulletin, 2017.

[6] Meng W, Hu B, He M, et al. Temporal-spatial variations and driving factors analysis of coastal reclamation in China [J]. Estuarine, Coastal and Shelf Science, 2017, 191: 39-49.

[7] Murray N J, Clemens R S, Phinn S R, et al. Tracking the rapid loss of tidal wetlands in the Yellow Sea [J]. Frontiers in Ecology and the Environment, 2014, 12(5): 267-272.

[8] Wang X, Li H, Meng W. Ecological impacts of marine reclamation in Binhai New Area of Tianjin[C]//Bioinformatics and Biomedical Engineering,(iCBBE) 2011 5th International Conference on. IEEE, 2011: 1-4.

[9] Hua Z L, Geng Y, Gu L. Advances in researches on environmental impacts and ecological effects of reclamation of tidal flats [J]. Journal of Economics of Water Resources, 2012, 30(3): 66-69, 84. (In China)

[10] Peng B R, Hong H S, Chen W Q, et al. Ecological damage appraisal of sea reclamation: theory, method and application [J]. Journal of Natural resources, 2005, 20(5): 714-726.

[11] Zhang H, Sun Y. Loss Appraisal on the Value of Marine Ecosystem Services of Sea Reclamation for Qianwan [J]. Transactions of Oceanology and Limnology, 2009, 3: 34-38.

[12] Ni J, Qin H. Assessment of reclamation impact on inter-tidal habitat loss [J]. Acta Scientiae Circumstantiae, 2003, 23(3): 345-349.

[13] XIE T, HU Y, GUO P. Influence of reclamation land project from marshes on marine environment and countermeasures of protection in Zhoushan [J]. Marine Environmental Science, 2009: S1.

[14] Zhang M H, Chen C P, Suo A N, et al. International advance of sea areas reclamation impact on marine environment [J]. Ecology and Environmental Sciences, 2012, 21(8): 1509-1513. (In China)

[15] Lin M C. Problems and Countermeasures of tideland reclamation in Fujian coastal area [J]. Forestry Prospect and Design, 2006(1): 98-100. (In China)

[16] Chen H Y, Xu G H. Environmental impact of reclamation and development of tidal flats in Jiangsu [J]. Water Resources Planning and Design, 2004(1): 18-21. (In China)

[17] He M H. Environmental impacts of harbor reclamation [J]. Ocean and Coastal-Zone Developmnt, 1988(3): 33-35, 38. (In China)

[18] Lie H J, Cho $\mathrm{C} \mathrm{H}$, Lee $\mathrm{S}$, et al. Changes in marine environment by a large coastal development of the Saemangeum reclamation project in Korea $[\mathrm{J}]$. Ocean and Polar Research, 2008, 30(4): 475-484.

[19] Zainal K, Al-Madany I, Al-Sayed H, et al. The cumulative impacts of reclamation and dredging on the marine ecology and land-use in the Kingdom of Bahrain [J]. Marine pollution bulletin, 2012, 64(7): 1452-1458.

[20] SHEN Y, FENG N, Zhou Q, et al. The status and its influence of reclamation on Jiangsu coast [J]. Marine Sciences, 2006, 10: 008. 
[21] Liu D H, Yu Y, Li X X, et al. Progress on the Environmental Impact Assessment of Coastal Reclamation in China [J]. Coastal Engineering, 2016, 35(3): 74-82. (In China)

[22] Ge Y, Jun-yan Z. Analysis of the impact on ecosystem and environment of marine reclamation--A case study in Jiaozhou Bay [J]. Energy Procedia, 2011, 5: 105-111.

[23] Yan B L, Qiu J. Analysis on impact of coastal reclamation project on flood drainage of river basin $[\mathrm{J}]$. Yangtze River, 2010, 41(3): 15-18. (In China)

[24] Zhang C K, Chen J, Lin K, et al. Spatial layout of reclamation of coastal tidal flats in Jiangsu Province[J]. Journal of Hohai University: Natural Sciences, 2011, 39(2): 206-212.

[25] Li J L, Yang X P, Tong Y Q. Progress on environmental effects of tidal flat reclamation [J]. PROGRESS IN GEOGRAPHY, 2007, 26(2): 43-51. (In China)

[26] Zhang C K, Chen X D. Offshore environmental changes and countermeasures in response to large-scale tidal flat reclamation $[\mathrm{J}]$. Journal of Hohai University (Natural Sciences), 2015, 43(5): 424-430. (In China)

[27] Zhang C, Zheng J H, Liu G P, et al. Hydrodynamic characteristics in nearshore sea areas in Jiangsu Province and their responses to reclamation projects $[\mathrm{J}]$. Journal of Economics of Water Resources, 2012, 30(3): 6-9, 81. (In China)

[28] Chen J B, Wang C, Zheng C Y, et al. Key technologies for large-scale reclamation and protection of tidal flats in coastal areas [J]. Journal of Economics of Water Resources, 2012, 30(3): 1-5, 81. (In China)

[29] Sladkevich M, Militeev A N, Rubin H, et al. Simulation of transport phenomena in shallow aquatic environment[J]. Journal of Hydraulic Engineering, 2000, 126(2): 123-136.

[30] Ou J, Ma J R, Zhang X Y, et al. Tidal Flow Numerical Simulation of the Reclamation Projects at Estuary and Beach [J]. Water Power, 2006, 32(3): 13-17. (In China)

[31] Zhang Q, Tao J F, Zhang C K, et al. Effect of the large-scale reclamation of tidal flats on the hydrodynamic characteristics in the Taizhou Bay [J]. MARINE SCIENCE BULLETIN, 2015, 34(4): 392-398. (In China)

[32] Chen D X, Chen M Y, Zhang C. Influence of reclamation projects on hydrodynamic force in offshore and estuary of Wenzhou $[\mathrm{J}]$. Journal of Hohai University (Natural Sciences), 2009, 37(4): 457-462. (In China)

[33] Lv H N. The study on the effect of coast reclamation engineering on hydrodynamic force in Oujiang estuary [D]. Ningbo University, 2015. (In China)

[34] Song Z K, Cheng H Q, Hu H, et al. Numerical simulation analysis of influence of reclamation of north branch in the Yangtze River estuary on hydrodynamic characteristics [J]. Yangtze River, 2012, 43(15): 59-63. (In China)

[35] Tao J F, Zhang C K, Yao J. Effect of large-scale reclamation of tidal flats on tides and tidal currents in offshore areas of Jiangsu Province [J]. Journal of Hohai University (Natural Sciences), 2011, 39(2): 225-230. (In China)

[36] Cushman-Roisin B, Naimie C E. A 3D finite-element model of the Adriatic tides [J]. Journal of Marine Systems, 2002,
37(4): 279-297.

[37] Liu X D, Tu Q L, Hua Z L, et al. Numerical simulation of hydrodynamic impact on coastal waters of Tiaozini reclamation project $[\mathrm{C}] / /$ China Ocean Press, 2015: 1177-1182. (In China)

[38] Wang Q, Li X, Huang H M, et al. Analysis on Effects of Tidal Flat Reclamation on the Wind Wave's Field in Jiangsu Coast[J]. Journal of Jiangnan University (Natural Science Edition), 2015, 14(1): 90-96. (In China)

[39] Fan C J, Li R J, Dai L, et al. Effects of tidal flat reclamation on wave's field in Jiangsu coast $[\mathrm{J}]$. Port \& Waterway Engineering, 2015(12): 16-22. (In China)

[40] ji Y J, Liu D J, Huang P Y, et al. Influence analysis of sediment dynamics and seabed evolution in adjacent channel under Zhoushan islands reclamation project [J]. Journal of Waterway and Harbor, 2015, 36(2): 112-120. (In China)

[41] Hu X Y, Zhou X H, Liu F, et al. Research on environmental problems caused by reclamation and Discussion on Management Countermeasures[J]. Ocean Development and Management, 2009, 26(10): 80-86. (In China)

[42] Gong Z, Dou X P, Zhang C K, et al. Influence of tidal flat reclamation on channel sedimentation downstream of tidal sluice in Jiangsu coastal zone [J]. YDRO-SCIENCE AND ENGINEERING, 2010(1): 73-78. (In China)

[43] Wang L S, Fang Z J, Huang H M. Influence of reclamation on suspended sediment field in Wenzhou estuarine and offshore waters [J]. Journal of Waterway and Harbor, 2008, 29(6): 386-393. (In China)

[44] Zhang R S. Influence of Reclamation of Supratidal Zone to Siltation of Flow Course below tidegate [J]. Journal of Nanjing Normal University (Natural Science), 1995, 18(2): 89-94. (In China)

[45] Ke J, Lu Y, Yao Q T, et al. Influences of planning reclamation project on hydrodynamic and sediment environment of Haizhou Bay [J]. Journal of Waterway and Harbor, 2016, 37(4): 356-361, 384. (In China)

[46] Chen P, Li R J, Dong X T, et al. Influence of reclamation project on hydrodynamic and sediment environment of Lianyungang sea area [J]. Port \& Waterway Engineering, 2016(3): 29-34, 56. (In China)

[47] Yang D C, Tao J F, Zhang C K. Impact of Haizhou bay tidal flat reclamation on siltation in the river downstream sluice in Linhong estuary [J]. Port \& Waterway Engineering, 2014(6): 96-101. (In China)

[48] Wang Y P, Gao S, Jia J, et al. Sediment transport over an accretional intertidal flat with influences of reclamation, Jiangsu coast, China [J]. Marine Geology, 2012, 291: 147-161.

[49] Shi H D, Shen Y M, Kang M. Rapid response of tidal creek network patterns to the reclamation on the central Jiangsu coast [J]. Acta Oceanologica Sinica, 2016, 38(1): 106-115. (In China)

[50] Qu W X, Zhang Y, Liu Y C. Impacts of reclamation on coastal topography in Sheyang Estuary $[\mathrm{J}]$. Journal of Hohai University (Natural Sciences), 2012, 40(2): 220-223. (In China) 